\title{
Commentary: Three reasons for paralysis after elephant trunk procedures
}

\author{
Lars G. Svensson, MD, PhD
}

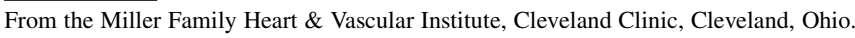 \\ Disclosures: Author has nothing to disclose with regard to commercial support. \\ Received for publication May 3, 2019; accepted for publication May 3, 2019; available ahead of print June 14, \\ 2019. \\ Address for reprints: Lars G. Svensson, MD, PhD, Heart \& Vascular Institute Cleveland Clinic, 9500 Euclid Ave, \\ Mail Stop J1-227, Cleveland, OH 44195 (E-mail: svenssl@ ccf.org). \\ J Thorac Cardiovasc Surg 2019;158:351-2 \\ $0022-5223 / \$ 36.00$ \\ Copyright (c) 2019 by The American Association for Thoracic Surgery \\ https://doi.org/10.1016/j.jtcvs.2019.05.017
}

Development of spinal cord injury (SCI) after elephant trunk procedures, including frozen elephant trunk (FET) procedures, has been recognized for 3 decades. ${ }^{1}$ Indeed, early in the experience with the classic elephant trunk procedure and graft inversion, paralysis was noted when the elephant trunk tube was long, and the recommendation was therefore made to keep it 10 to $15 \mathrm{~cm}$ in length. ${ }^{1}$ In a prospective, randomized trial of total aortic replacement, in which two-thirds of patients had elephant trunk procedures, mortality was $0.8 \%$, occurrence of stroke was $0.8 \%$, and no patients had SCI develop. ${ }^{2}$ None underwent the FET procedure. Furthermore, in an evaluation of 526 elephant trunk procedures (no FET procedures), prevalence of SCI was $0.4 \% .^{3}$ In contrast, in a German study of aortic dissection, increasing use of endovascular stents for type A and type B dissection was associated with $20 \%$ mortality and $12 \%$ SCI and with $9.3 \%$ mortality and $6.7 \%$ SCI, respectively, ${ }^{4}$ although these data need careful interpretation. ${ }^{5}$

What is the cause of SCI after total arch repair? In their article in this issue of the Journal, Tan and colleagues, ${ }^{6}$ on the basis of 4 patients, suggest that the etiology of SCI after FET is compression of the true lumen and argue that SCI is related to 30 to $60 \mathrm{~mm}$ of false-lumen thrombosis.

Previously, on the basis of both animal research and retrospective studies, I believed that SCI was due to (1) degree of ischemia during aortic clamping; (2) failure to reperfuse critical intercostal or lumbar arteries, particularly below T8; and (3) delayed reperfusion injury or inadequate perfusion. ${ }^{7}$ Reason 1 usually will not apply to FET, because the procedure is done with hypothermia and generally brief periods of ischemia to the spinal cord. Nevertheless, it does appear that SCI is more prone to occur with deep hypothermia and arch surgery, especially FET, perhaps because of reason $3 .^{8}$ In relation to reason 2 , early studies, apart from our experience with elephant trunk, showed that longer coverage by FET, particularly below T7, was associated with more SCI. ${ }^{3,9-12}$ Tan and colleagues' suggestion ${ }^{6}$ to

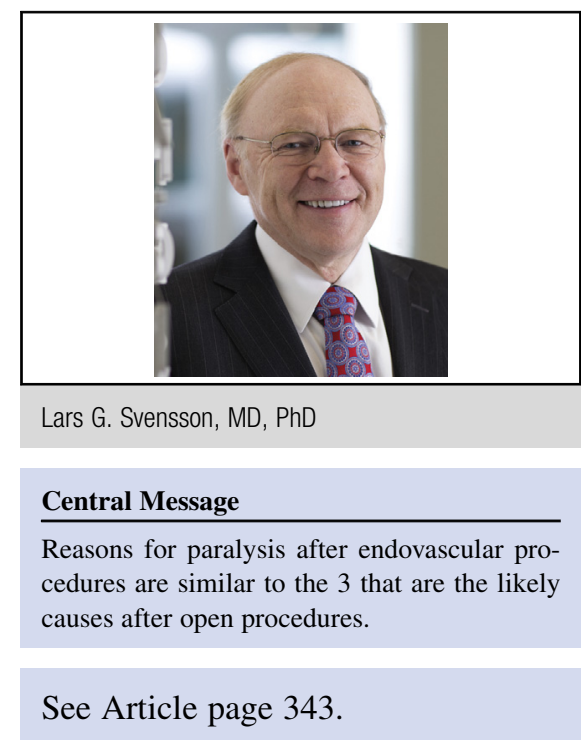

use longer FET thus should not be followed. In their series, however, reason 3 was clearly a factor, namely failure of reperfusion of the spinal cord, either because of thrombosis of the false lumen with obstruction of the arising intercostal and lumbar arteries from the segment or, clearly, failure to reperfuse the distal true lumen because of its collapse. This would mean that even if patient intercostal or lumbar arteries were present, the distal pressure was not adequate to perfuse them, and this would be in addition to the risk of SCI from hypothermia and cardiopulmonary bypass with arch repair.

Tan and colleagues ${ }^{6}$ again, as with both elephant trunk and FET procedures, warn us of the danger of leaving behind a small true lumen rather than dealing with it. Either a bare metal stent or, less so, an additional covered stent will improve distal flow and allow the prevention of reason 3 , namely a failure of reperfusion, a lesson learned many years ago. ${ }^{10,11}$

\section{References}

1. Svensson LG. Rationale and technique for replacement of the ascending aorta arch, and distal aorta using a modified elephant trunk procedure. J Card Surg. 1992; 7:301-12.

2. Svensson LG, Blackstone EH, Apperson-Hansen C, Ruggieri PM, Ainkaran P, Naugle RI, et al. Implications from neurologic assessment of brain protection for total arch replacement from a randomized trial. J Thorac Cardiovasc Surg. 2015;150:1140-7.e11.

3. Svensson LG, Rushing GD, Valenzuela ES, Rafael AE, Batizy LH Blackstone EH, et al. Modifications, classification, and outcomes of elephanttrunk procedures. Ann Thorac Surg. 2013;96:548-58.

4. Reutersberg B, Salvermoser M, Trenner M, Geisbusch S, Zimmermann A, Eckstein $\mathrm{HH}$, et al. Hospital incidence and in-hospital mortality of surgically 
and interventionally treated aortic dissections: secondary data analysis of the nationwide German diagnosis-related group statistics from 2006 to 2014. J Am Heart Assoc. 2019;8:e011402.

5. Svensson LG. Are we there yet? Emerging milestones in aortic dissection care. $J$ Am Heart Assoc. 2019;8:e012402.

6. Tan L, Xiao J, Zhou X, Shen K, Li F, Luo J, et al. Untreated distal intimal tears may be associated with paraplegia after total arch replacement and frozen elephant trunk treatment of acute Stanford type A aortic dissection. J Thorac Cardiovasc Surg. 2019;158:343-50.e1.

7. Svensson LG, Von Ritter CM, Groeneveld HT, Rickards ES, Hunter SJ, Robinson MF, et al. Cross-clamping of the thoracic aorta. Influence of aortic shunts, laminectomy, papaverine, calcium channel blocker, allopurinol, and superoxide dismutase on spinal cord blood flow and paraplegia in baboons. Ann Surg. 1986;204:38-47.
8. Svensson LG. Device discordancy: lost cords, quick-fix seekers, quality, and ethics. J Thorac Cardiovasc Surg. 2006;131:261-3.

9. Flores J, Kunihara T, Shiiya N, Yoshimoto K, Matsuzaki K, Yasuda K. Extensive deployment of the stented elephant trunk is associated with an increased risk of spinal cord injury. J Thorac Cardiovasc Surg. 2006;131:336-42.

10. Suto Y, Yasuda K, Shiiya N, Murashita T, Kawasaki M, Imamura M, et al. Stented elephant trunk procedure for an extensive aneurysm involving distal aortic arch and descending aorta. J Thorac Cardiovasc Surg. 1996;112:1389-90.

11. Kato M, Ohnishi K, Kaneko M, Ueda T, Kishi D, Mizushima T, et al. New graftimplanting method for thoracic aortic aneurysm or dissection with a stented graft Circulation. 1996;94(9 Suppl):II188-93.

12. Roselli EE, Idrees JJ, Bakaeen FG, Tong MZ, Soltesz EG, Mick S, et al. Evolu tion of simplified frozen elephant trunk repair for acute DeBakey Type I dissection: midterm outcomes. Ann Thorac Surg. 2018;105:749-55. 